\title{
Análise numérica de vigas mistas aço-concreto em temperatura ambiente e em situação de incêndio
}

\section{Numerical analysis of composite steel-concrete beams in ambient temperature and in fire situation}

\author{
Larissa Degliuomini Kirchhof ${ }^{1}$; Jorge Munaiar Neto ${ }^{2}$; \\ Maximiliano Malite²; Roberto Martins Gonçalves².
}

\begin{abstract}
Resumo
Neste trabalho são propostos modelos numéricos tridimensionais de vigas mistas aço-concreto simplesmente apoiadas, considerando-se apenas a interação total (desconsideração de deslocamentos relativos entre laje de concreto e viga de aço). Os modelos são construídos com vistas a simular o comportamento de vigas mistas, em temperatura ambiente e em situação de incêndio, utilizadas na prática da construção. Utiliza-se, para a modelagem numérica, o programa ABAQUS versão 6.3-1 elaborado com base no Método dos Elementos Finitos. Os resultados numéricos obtidos são comparados com resultados experimentais apresentados por outros pesquisadores. Os resultados numéricos, quando comparados com resultados experimentais, demonstram que os modelos elaborados com elementos finitos do tipo casca apresentam melhor desempenho quando comparados com os modelos elaborados com elementos finitos do tipo sólido.
\end{abstract}

Palavras-chave: Estruturas Metálicas. Vigas Mistas Aço-concreto. Incêndio. Análise Numérica.

\begin{abstract}
This paper presents three-dimensional numerical models of steel-concrete composite beams with full interaction (no slip between concrete slab and steel beam) using a non-linear procedure. The threedimensional numerical models must be capable of predicting the response of composite beam at ambient temperature and in fire situation with accuracy. The computer program ABAQUS ${ }^{\circledR}$ 6.3-1, based on Finite Element Method, was used to analyze the numerical modeling. The accuracy of the models is demonstrated through the results obtained, which are compared with the experimental results presented in other works. The reported results, when compared to experimental data, demonstrate that the numerical models elaborated with shell finite elements show better performance when compared to the results of the numerical models elaborated with solid finite elements.
\end{abstract}

Key words: Structures. Composite Beams. Fire Situation. Numerical Analysis.

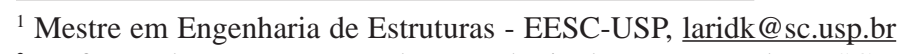

${ }^{2}$ Professor do Departamento de Engenharia de Estruturas da EESC-USP, jmunaiar@sc.usp.br 


\section{Introdução}

No Brasil, e em outros países, os sistemas estruturais mistos têm sido bastante utilizados na construção civil (por exemplo, edifícios comerciais e industriais). Podem ser citados, como exemplos, as lajes mistas aço-concreto (lajes de concreto com fôrma de aço incorporada), os pilares mistos açoconcreto (pilares de aço protegidos ou preenchidos com concreto) e as vigas mistas aço-concreto (lajes de concreto sobre vigas de aço).

No contexto mundial, estudos referentes aos sistemas compostos tiveram seu início antes da Primeira Grande Guerra, na Inglaterra, com base em uma série de ensaios para pisos. Entre 1922 e 1939, foram construídos edifícios e pontes que adotavam o sistema de vigas compostas, conforme mencionado em Malite (1990). Vale mencionar que entre os anos de 1920 e 1958, muitas pesquisas foram desenvolvidas e publicadas, com referência ao comportamento estrutural de vigas mistas açoconcreto, em países como Estados Unidos, Inglaterra, Canadá entre outros (VIEST,1960).

No Brasil, a construção mista limitou-se a alguns edifícios e pequenas pontes, entre 1950 e 1960. A partir da década de 70 e início da década de 80, a utilização de sistemas mistos praticamente ficou estagnada, dando-se maior preferência pelo uso do concreto armado e do concreto protendido nas edificações correntes (MALITE, 1993). Com o aumento da produção de aço no Brasil e objetivando novas soluções arquitetônicas e estruturais, a utilização de sistemas mistos vem crescendo consideravelmente na construção de edifícios industriais, comerciais, pontes, etc.

A utilização deste sistema é viável e de grande vantagem, pois, como se sabe, o aço apresenta boa resposta quando submetido a esforços de tração, enquanto o concreto apresenta boa resposta quando submetido a esforços de compressão. Além disso, a associação dos materiais aço e concreto resulta em um acréscimo de resistência e rigidez para o sistema misto, proporcionando reduções na altura dos elementos estruturais e, conseqüentemente, economia de materiais.

As vigas mistas aço-concreto, objeto de estudo do presente trabalho, são constituídas pela associação entre vigas de aço e lajes de concreto armado. A norma brasileira NBR 8800:1986 - Projeto e execução de estruturas de aço de edifícios trata do dimensionamento, em temperatura ambiente, de elementos estruturais de aço e também de vigas mistas aço-concreto.

Também merece destaque, para fins de projeto em estruturas metálicas, a questão do aço em situação de incêndio. Com a publicação das normas brasileiras NBR 14323, Dimensionamento de estruturas de aço de edifícios em situação de incêndio (ABNT, 1999) e NBR 14432, Exigências de resistência ao fogo de elementos construtivos de edificações (ABNT, 2000), muitos são os assuntos de interesse que estão surgindo com relação à resistência dos elementos estruturais de aço e mistos em situação de incêndio.

Atualmente, as normas NBR 8800 (ABNT, 1986) e NBR 14323 (ABNT, 1999) passam por processo de revisão, de modo que alguns valores prescritos no projeto de revisão, como os fatores de redução da resistência e da rigidez dos materiais aço e concreto em função da temperatura, serão previamente considerados nas modelagens numéricas de vigas mistas aço-concreto em situação de incêndio.

Nesse sentido, o presente trabalho propõe a elaboração de modelos numéricos tridimensionais para viga mista aço-concreto simplesmente apoiada, por meio da utilização do programa $A B A Q U S$ versão 6.3-1, elaborado com base no Método dos Elementos Finitos. O objetivo principal é simular o comportamento estrutural de vigas mistas, em temperatura ambiente e em situação de incêndio, e os resultados serão comparados com aqueles apresentados por outras referências bibliográficas pesquisadas. 


\section{Vigas mistas aço concreto - Breve abordagem}

As vigas mistas aço-concreto têm sido bastante empregadas em sistemas de pisos constituídos por vigas de aço e lajes de concreto. A eficiência da viga mista para resistir a esforços de flexão está associada a fatores como resistência à compressão do concreto e espessura da laje, tipo de aço, existência ou não de escoramento das lajes (fase de construção), interação entre viga e laje, entre outros.

Dentre os fatores citados, enfatiza-se o aspecto da interação entre viga e laje, garantida por meio de elementos chamados conectores de cisalhamento soldados na mesa superior da viga de aço (MALITE, 1990). Esse procedimento consiste em garantir que viga e laje trabalhem em conjunto para resistir, com maior eficiência, a esforços de flexão e tem por função transmitir o fluxo de cisalhamento longitudinal que se gera na interface aço-concreto, bem como impedir o afastamento vertical entre viga e laje, fenômeno conhecido como uplift.

Dentre os diferentes tipos de conectores usualmente empregados em edifícios e pontes, salientam-se os perfis U (laminados) e os conectores tipo pino com cabeça (stud bolt), ambos do tipo flexível e os únicos previstos na norma NBR 8800 (ABNT, 1986), atualmente em vigor. A figura 1 ilustra os tipos de vigas mistas mais empregados em edificações, em que se utilizam conectores de cisalhamento do tipo pino com cabeça.

Com relação aos tipos de interações, neste caso, nula, completa ou parcial, esquematizadas na figura 2, vale mencionar que parte da eficiência das vigas mistas está diretamente relacionada ao trabalho em conjunto entre viga e laje. A interação total (ou completa), objeto de interesse no presente trabalho, é considerada ao se admitir uma ligação efetiva entre viga e laje, ou seja, inexistência de escorregamentos longitudinais relativos entre viga e laje.

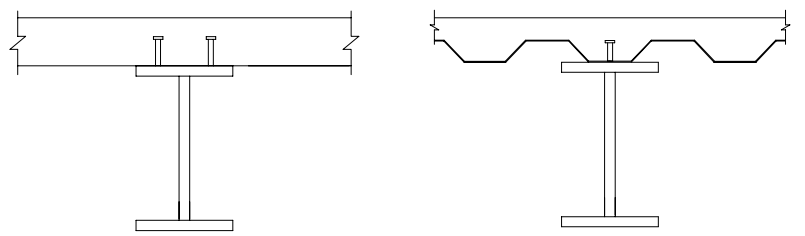

Figura 1 . Tipos mais usuais de seções de vigas mistas aço-concreto (MALITE, 1990).

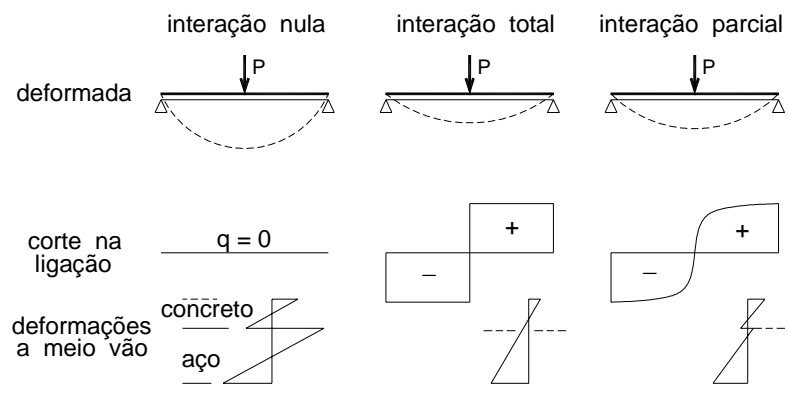

Figura 2. Interação entre a viga de aço e laje de concreto (MALITE, 1990).

\section{Estruturas de aço e mista aço-concreto em Situação de incêndio}

O tema incêndio, dentro do contexto das estruturas de aço, parecia ser um aspecto sem solução devido à inexistência de códigos normativos para uma adequada orientação do meio técnico quanto à minimização desse problema.

No entanto, esse tema deixou de ser um problema em razão da publicação, em 1999, da norma brasileira NBR 14323 - Dimensionamento de estruturas de aço de edifícios em situação de incêndio, (ABNT, 1999). Para a aplicação do procedimento simplificado da NBR 14323, percebeu-se a necessidade de uma norma para determinação da ação térmica nos elementos construtivos dos edifícios. Para tanto, foi publicada em 2000 a NBR 14432 - Exigências de resistência ao fogo de elementos construtivos das edificações, (ABNT, 2000)

A consideração da ação térmica no aço e no concreto deve-se ao fato de a exposição desses materiais a temperaturas elevadas provocar alterações em suas propriedades mecânicas. Isso pode ser traduzido na forma de reduções nos valores 
do módulo de elasticidade (E) e da resistência ao escoamento do aço ( $\left.f_{\mathrm{y}}\right)$, bem como nos valores do módulo de elasticidade $\left(\mathrm{E}_{\mathrm{c}}\right)$ e da resistência à compressão do concreto $\left(\mathrm{f}_{\mathrm{ck}}\right)$, conforme esquematiza a figura 3. Tais reduções constituem aspectos que devem ser levados em conta no dimensionamento das estruturas de aço e mistas em situação de incêndio, e também serão levados em conta no presente trabalho, quando das análises em situação de incêndio.

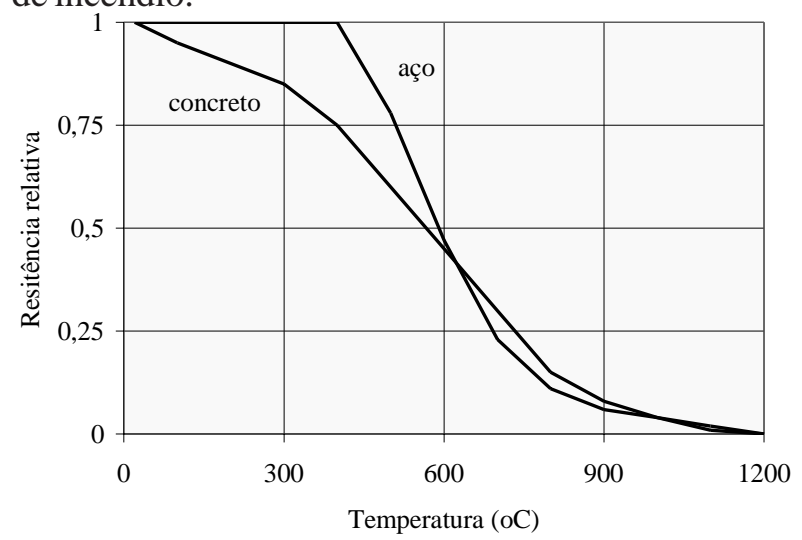

(a)

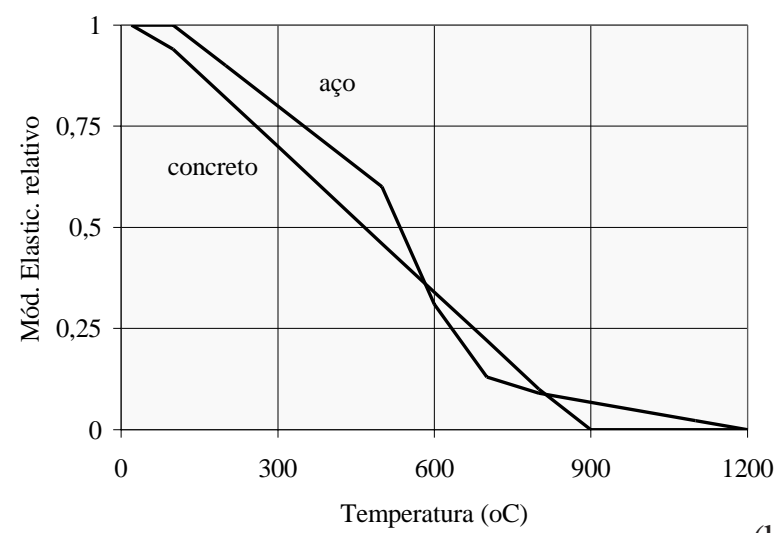

(b)

Figura 3. Reduções nas propriedades do aço e do concreto, em função da temperatura.

(a) resistência relativa e (b) módulo de elasticidade relativo.

\section{Aspectos da modelagem numérica}

A complexidade da análise multiaxial, nos campos das tensões e das deformações, conduz à utilização de modelos matemáticos (analíticos) bastante complexos, descritos por equacionamentos custosos, conforme verificado nos procedimentos de modelagem propostos em Oven et al. (1997) e em Gattesco (1999). Atualmente, com a evolução dos micro-computadores e dos códigos de cálculo para análise estrutural, a análise multiaxial (plana ou tridimensional) para as estruturas, de um modo geral, deixa de ser um problema.

Nesse sentido, são aqui analisadas vigas mistas aço-concreto por meio de simulações numéricas com vistas ao comportamento global do sistema misto, propondo-se modelos numéricos tridimensionais para simular seu comportamento estrutural em temperatura ambiente e em situação de incêndio. A simulação numérica será realizada por meio da utilização do código de cálculo $A B A Q U S$ versão 6.31, elaborado com base no Método dos Elementos Finitos, o qual disponibiliza ao pesquisador os recursos necessários para as modelagens de interesse.

Nos itens que se seguem serão apresentados os aspectos considerados para os modelos numéricos propostos, em temperatura ambiente e em situação de incêndio, os elementos finitos adotados para a discretização, as relações constitutivas, bem como as condições de contorno e carregamento.

\section{Modelos numéricos de vigas mistas simplesmente apoiadas - Análise em temperatura ambiente}

Elementos finitos utilizados

O ABAQUS possui uma extensa biblioteca de elementos finitos que fornece ao usuário ferramentas numéricas para a resolução de diferentes problemas práticos. A escolha dos elementos para a simulação numérica deve ser feita levando-se em consideração vários aspectos, tais como a família a qual o elemento pertence, os graus de liberdade ativos, o número de nós e, principalmente, o comportamento que ele apresenta perante a análise desejada.

Para a elaboração do modelo numérico de vigas mista em temperatura ambiente, foram utilizados os seguintes elementos finitos: 
- Sólido C3D8R - O elemento sólido (ou contínuo), denominado por C3D8R, ilustrado na figura 4(a), é um elemento finito tridimensional que possui 8 (oito) nós, com 3 (três) graus de liberdade por nó, referentes às translações nas direções $\mathrm{X}, \mathrm{Y}$ e Z (coordenadas globais). Este elemento foi utilizado para discretizar tanto o perfil metálico como também a laje de concreto.

- Treliça T3D2 - O elemento treliça T3D2, ilustrado na figura 4(b) é utilizado para discretizar as armaduras transversais e longitudinais. Possui 2 (dois) nós, apresentando 3 (três) graus de liberdade por nó, referentes às translações nas direções X, Y e Z. Este elemento é usado somente para transmitir forças axiais e, conseqüentemente, admite carregamentos apenas ao longo do eixo do elemento, visto que não possui rigidez para resistir a solicitações perpendiculares ao seu eixo.

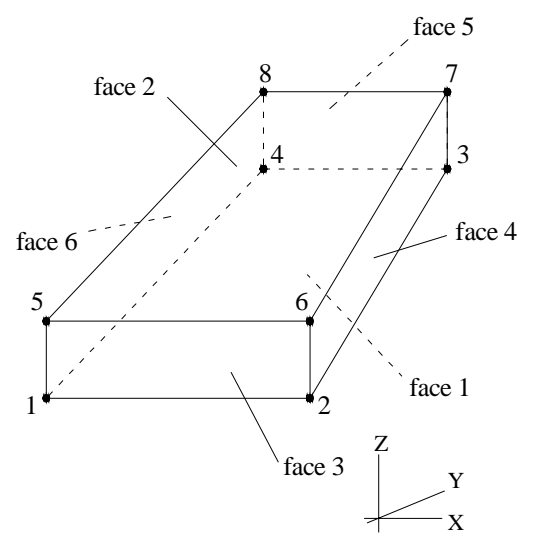

(a)

Figura 4. Elementos finitos utilizados para a discretização: (a) C3D8R, (b) T3D2 e (c) S4R.

\section{Condições de contorno e de carregamento}

O modelo numérico proposto para análise em temperatura ambiente foi construído em concordância com as geometrias apresentadas em Huang, Burgess e Plank (1999), o qual, por sua vez, tomou como base resultados de um ensaio experimental descrito em Chapman e Balakrishnan (1964) para uma viga mista simplesmente apoiada, cujas condições de contorno e de carregamento estão ilustradas na figura 5.
- Shell S4R - O elemento finito Shell, denominado S4R, ilustrado na figura 4(c), possuí 4 (quatro) nós, com 6 (seis) graus de liberdade por nó, referentes as translações $\left(u_{x}, u_{y}\right.$ e $\left.u_{z}\right)$ e as rotações $\left(f_{x}, f_{y}\right.$ e $\left.f_{z}\right)$ segundo as coordenadas X, Y e Z. O elemento $S 4 R$ foi também utilizado para discretizar a laje de concreto, com vistas a comparar a eficiência dos modelos numéricos construídos com este elemento, no referente à estabilidade numérica, com aqueles construídos com o elemento finito $C 3 D 8 R$.

- Elemento REBAR - O elemento finito REBAR foi utilizado para definir as camadas de armaduras que estarão inseridas no elemento Shell S4R. É necessário informar ao ABAQUS o espaçamento entre as armaduras na direção desejada, a área da seção transversal de cada barra, bem como a posição de cada camada de armaduras na espessura.

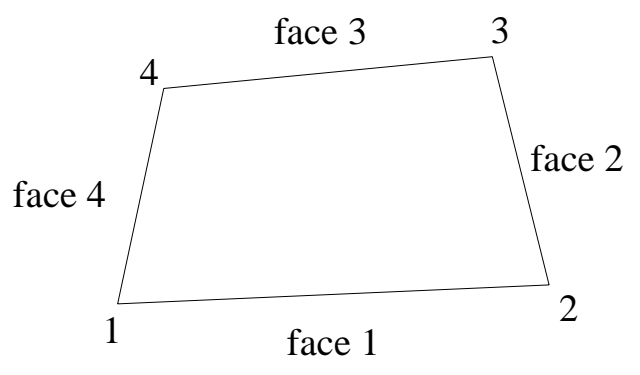

(b)

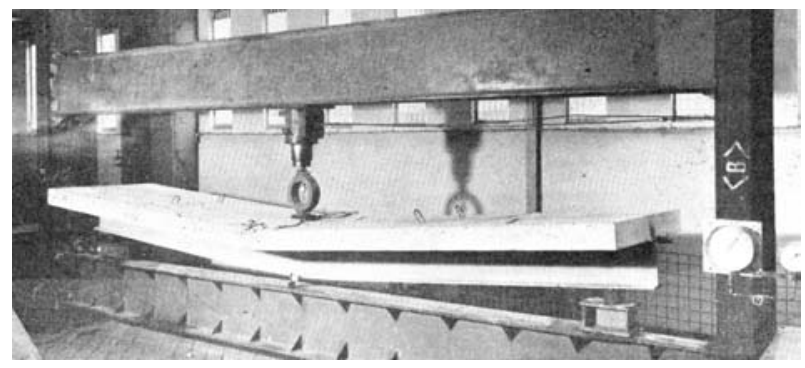

Figura 5. Viga mista ensaiada com carregamento concentrado no meio do vão. 
O carregamento concentrado é aplicado no meio do vão e coincidente com o eixo da viga. A viga mista foi apoiada sobre roletes, localizados próximos de suas extremidades, e o carregamento pontual aplicado foi distribuído em uma pequena área por meio de uma chapa de aço associada a uma chapa de madeira. Os modelos numéricos foram construídos com base nas considerações descritas para o modelo experimental e ilustradas pela figura 5. A figura 6 ilustra as malhas, as condições de contorno e de carregamentos, utilizadas na construção dos modelos numéricos para análise em temperatura ambiente.
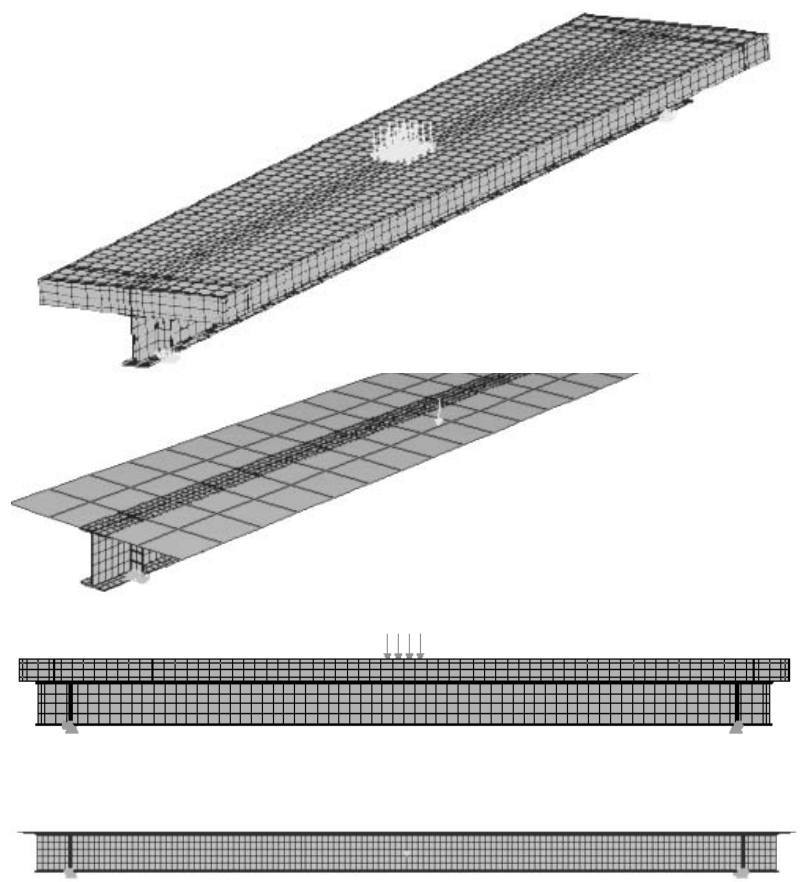

(a)

(b)

Figura 6 . Modelos numéricos de vigas mistas açoconcreto:

(a) laje construída com o elemento C3D8R e (b) laje construída com o elemento S4R.

Em ambos os modelos esquematizados nas figuras 6a e 6b, as translações do apoio esquerdo foram restringidas nas três direções globais (X, Y e Z), enquanto que para o apoio direito foram impedidas as translações vertical e transversal (Y e Z), deixando livre a translação na direção axial.

\section{Relações constitutivas adotadas}

Para o aço da armadura, foi adotada uma relação constitutiva (diagrama $\sigma \times \varepsilon$ ) do tipo elasto-plástico perfeito, associada ao critério de von Mises, com base na relação entre as tensões uniaxiais e suas respectivas deformações plásticas equivalentes. O comportamento adotado está representado por meio do diagrama tensãodeformação, ilustrado na figura 7(a).

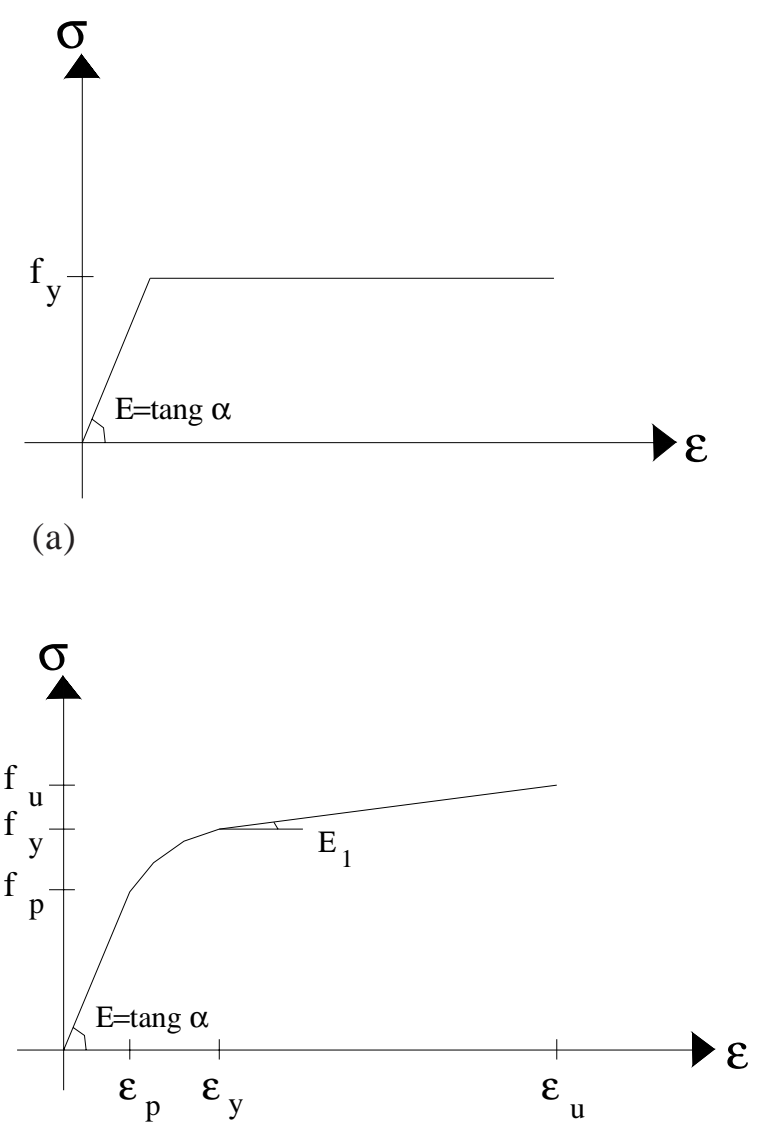

(b)

Figura 7. Relações constitutivas adotadas:

(a) Modelo elasto-plástico perfeito para as armaduras e (b) Modelo elasto-plástico multilinear com encruamento isótropo para a viga de aço.

A relação adotada para a viga de aço, também associada ao critério de von Mises, considera sucessivos trechos lineares por meio do diagrama $\sigma$ $\mathrm{x} \varepsilon$ conforme representado na figura 7 (b). Nesse caso, admite-se que o aço do perfil desenvolve deformações plásticas após atingir sua tensão de 
proporcionalidade $\left(\mathrm{f}_{\mathrm{p}}=0,7 \mathrm{f}_{\mathrm{y}}\right)$, como também permite o acréscimo de tensões até alcançar a resistência última $\left(\mathrm{f}_{\mathrm{u}}\right)$.

Para a laje de concreto, adotou-se o modelo CONCRETE disponibilizado na biblioteca interna do programa ABAQUS. O comportamento estrutural do concreto submetido à compressão é simulado por meio de uma relação constitutiva $\sigma \times \varepsilon$ do tipo elastoplástico multilinear, conforme figura 8(a). Já o comportamento do concreto submetido à tração é definido por meio da curva descendente denominada "tension stiffening”, representada na figura 8(b).

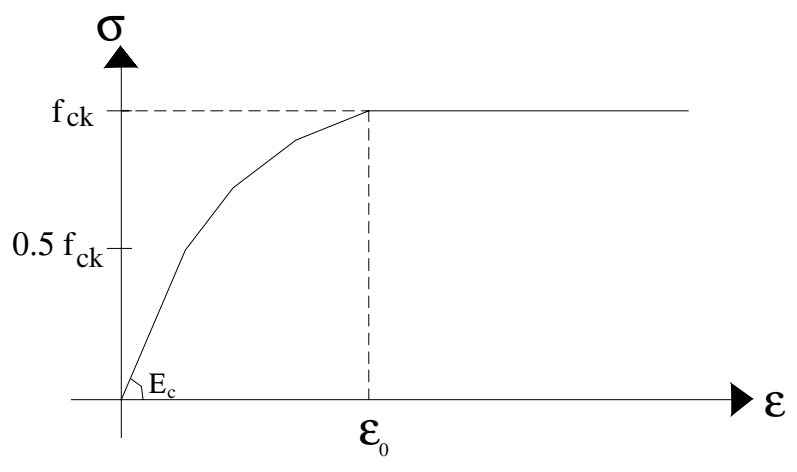

(a)

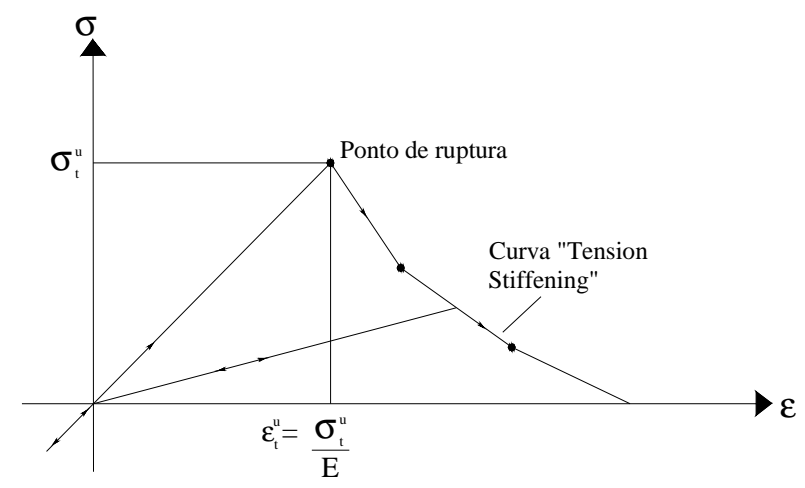

(b)

Figura 8. Diagramas tensão-deformação adotados para o concreto:

(a) na compressão e (b) Modelo "tension stiffening" na tração.

\section{Modelos numéricos de vigas mistas simplesmente apoiadas - Análise em situação de incêndio sem revestimento térmico}

Elementos finitos utilizados

A construção dos modelos numéricos para análise em situação de incêndio foi feita com a utilização dos mesmos elementos finitos adotados para a análise em temperatura ambiente, ou seja, o elemento sólido C3D8R para o perfil metálico, os elementos sólido C3D8R e shell S4R para a laje de concreto, e o elementos treliça T3D2 e REBAR para discretização das armaduras transversais e longitudinais. Suas propriedades estão de acordo com aquelas descritas no item 4.1.1.

\section{Relações constitutivas em função da temperatura}

Conforme mencionado no item 3, os materiais aço e concreto, quando expostos a elevadas temperaturas, sofrem alterações em suas propriedades mecânicas, causando reduções na resistência e na rigidez do sistema, aspectos que sempre devem ser levados em consideração quando do dimensionamento das estruturas em situação de incêndio.

Dessa forma, as simulações do comportamento estrutural da viga de aço, da laje de concreto e das armaduras, em função da temperatura, foram feitas de acordo com os modelos matemáticos apresentados no Eurocode 2 - Parte 1-2, (EUROPEAN COMMITEE FOR STANDARDIZATION, 1995), que trata do dimensionamento das estruturas de concreto em situação de incêndio, bem como de acordo com o Eurocode 4 - Parte 1-2, (EUROPEAN COMMITEE FOR STANDARDIZATION, 1994) que trata do dimensionamento das estruturas mistas aço-concreto em situação de incêndio. Os diagramas tensão-deformação para os aços estruturais e para o aço da armadura, em função da temperatura, EUROCODE 4, estão representados na figura 9. 


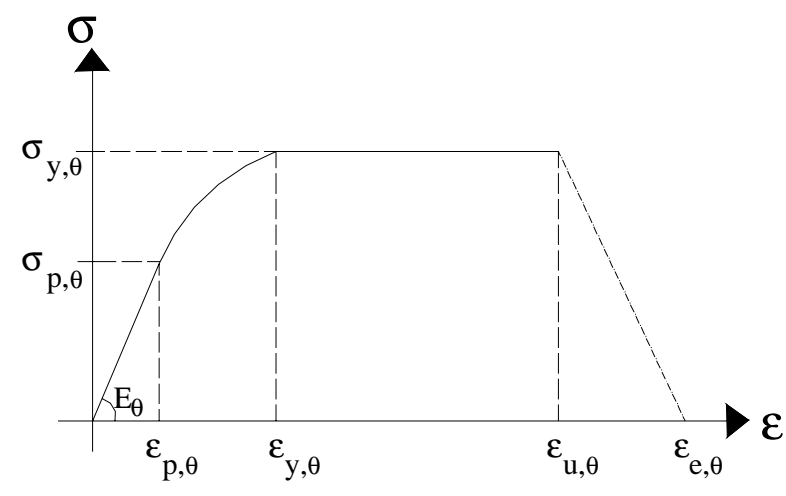

(a)

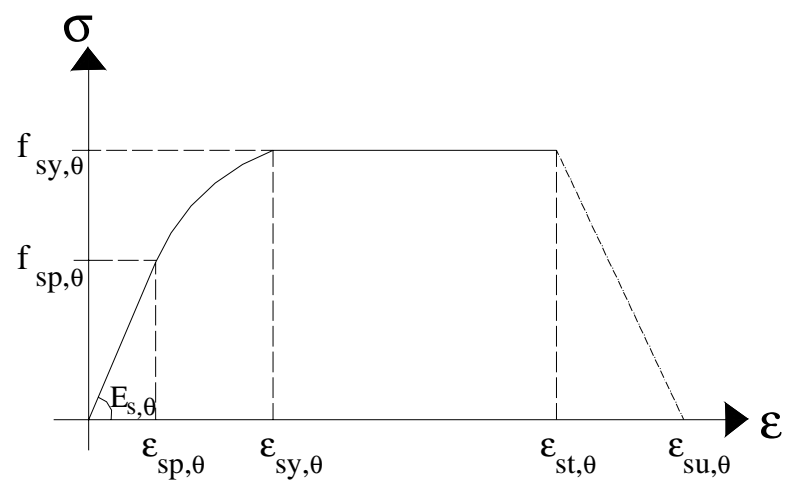

(b)

Figura 9. Diagrama tensão-deformação, conforme Eurocode 4-parte 1-2: (EUROPEAN COMMITE FOR STANDARDIZATION, 1994)

(a) aços estruturais submetidos à temperatura $\theta$ e (b) aço da armadura submetido à temperatura $\theta$.

O Eurocode 2 Parte 1-2 (EUROPEAN COMMITEE FOR STANDARDIZATION, 1995)propõe relações constitutivas para a resistência à compressão do concreto quando submetido a elevadas temperaturas, conforme apresentado na figura 10. A curva tensão-deformação para uma certa temperatura é definida por meio de dois parâmetros: a resistência característica à compressão $\mathrm{f}_{\text {ck }}(\theta)$ e a sua correspondente deformação $\varepsilon_{\mathrm{c} 1}(\theta)$.

Vale ressaltar que os modelos constitutivos utilizados no ABAQUS versão 6.3-1 para a simulação do comportamento do aço e do concreto não permitem valores decrescentes de tensão para definição dos ramos descendentes das curvas ilustradas nas figuras 9 e 10. Dessa forma, o diagrama tensão-deformação para o aço estrutural foi obtido até o trecho correspondente à deformação de 0,15 , enquanto o diagrama tensão-deformação para o concreto, após atingida a resistência à compressão em função da temperatura $\mathrm{f}_{\text {cke } \theta}$, foi considerado elasto-plástico perfeito.

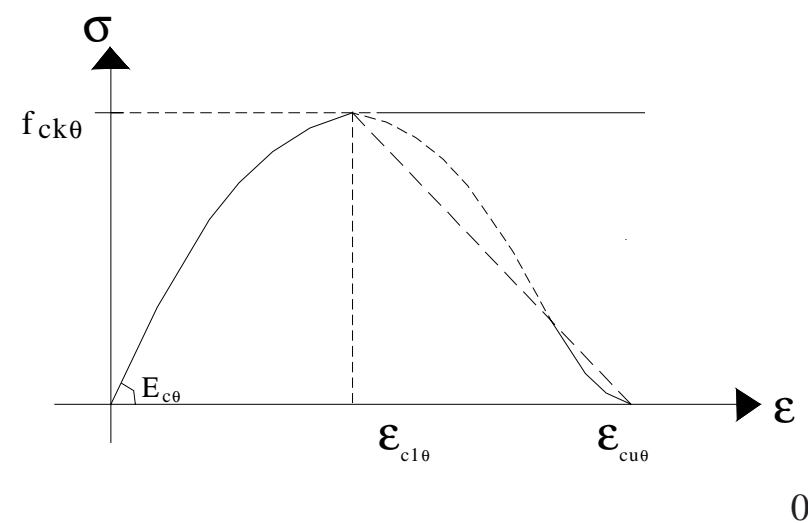

Figura 10. Diagrama tensão-de-formação para o concreto submetido à temperatura $\theta$, Eurocode 2 - Parte 1-2. (EUROPEAN COMMITEE FOR STANDARDIZATION, 1995)

\section{Condições de contorno e de carregamento}

As condições de contorno e de carregamento foram adotadas em concordância com aquelas usadas nos ensaios experimentais, em situação de incêndio, realizados em vigas mistas simplesmente apoiadas e descritos por Wainman e Kirby (1988 apud HUANG; BURGESS; PLANK, 1999), conforme figura 11. A figura 12 ilustra a malha de elementos finitos e as condições de contorno e de carregamento utilizadas na elaboração dos modelos numéricos em situação de incêndio, em concordância com o esquema da figura 11.

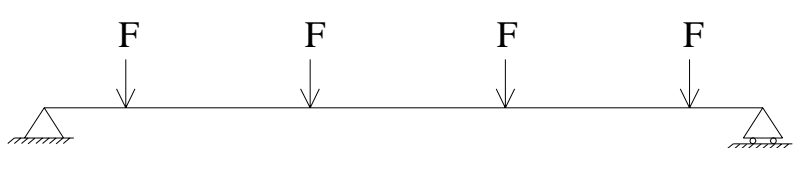

Figura 11. Esquema estrutural referente ao modelo experimental em situação de incêndio. 
Salienta-se, ainda, que a aplicação do carregamento estático e a aplicação da temperatura nos modelos numéricos foram executadas em etapas distintas. Primeiramente, foi aplicada aos modelos numéricos uma força $\boldsymbol{F}$ que pode ser considerada como uma solicitação de serviço e, portanto, não causa o colapso do sistema estrutural. Logo após, aplicouse incrementos de temperatura, de acordo com as prescrições da NBR 14323 (ABNT, 1999), com referência ao dimensionamento de vigas mistas açoconcreto em situação de incêndio.

A NBR 14323 (ABNT, 1999), prescreve que a distribuição de temperatura em vigas mistas sem revestimento térmico deve ser tomada como nãouniforme com a seção transversal dividida em três partes distintas, conforme figura 13: mesa inferior, alma (a temperatura na alma deve ser considerada igual à temperatura na mesa inferior) e mesa superior.
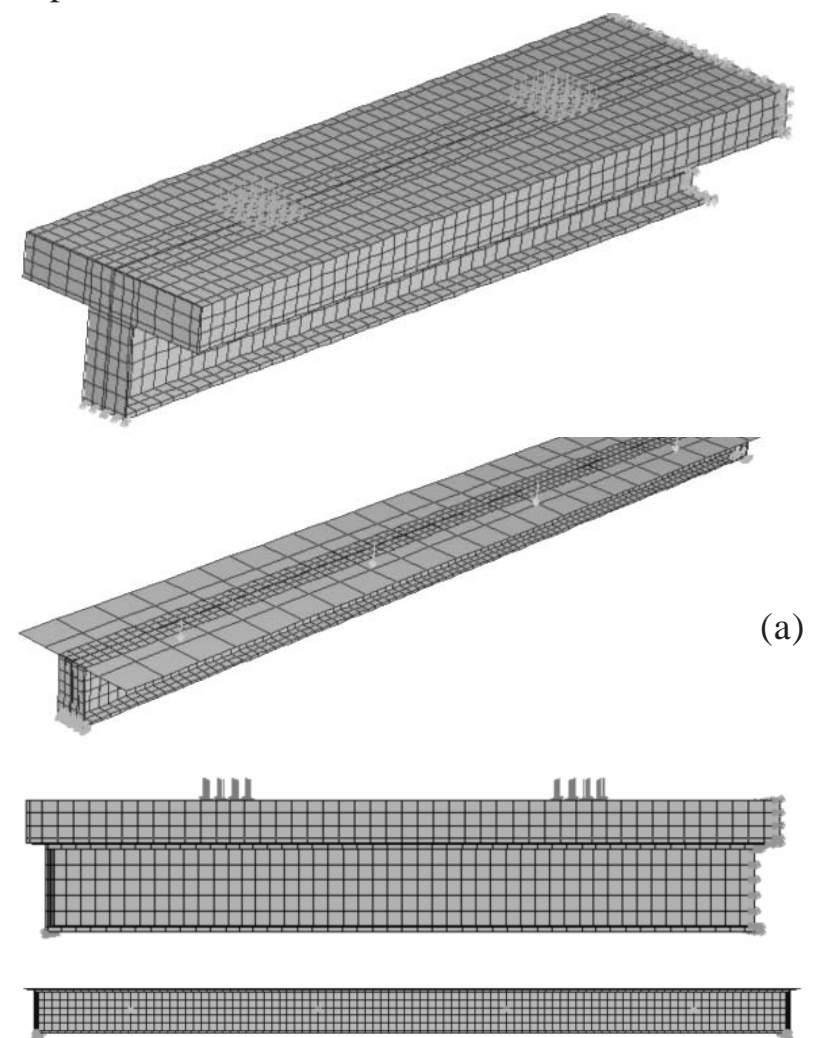

(b)

Figura 12. Modelos numéricos de vigas mistas açoconcreto, em situação de incêndio:

(a) laje construída com o elemento C3D8R e (b) laje construída com o elemento S4R.

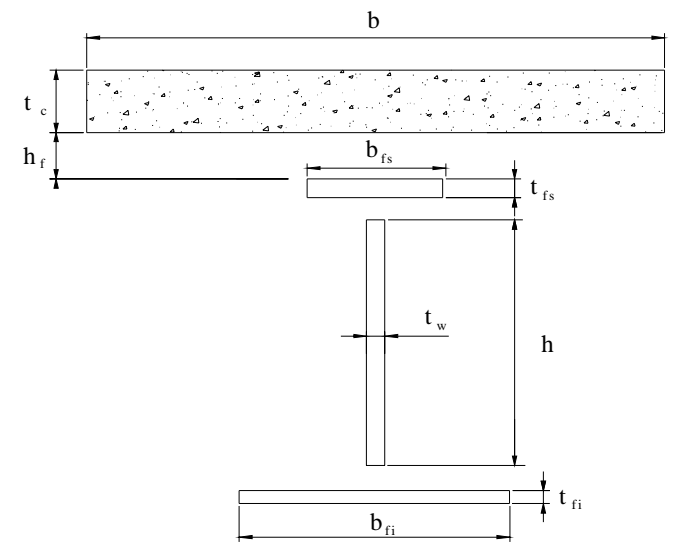

Figura 13. Divisão da seção da viga mista em setores submetidos a diferentes temperaturas.

O acréscimo de temperatura $\Delta \theta_{\mathrm{a}, \mathrm{t}}$ das mesas inferior e superior da viga de aço, durante o intervalo de tempo "t, foi determinado conforme item 8.5.1.1 apresentado na Norma NBR 14323 (ABNT, 1999), que trata dos elementos estruturais sem proteção contra incêndio, com base no fator de massividade, expresso pela relação entre o perímetro exposto ao fogo (u) e a área da seção transversal (A) do elemento em estudo, levando-se em conta as seguintes equações:

- para a mesa inferior:

$\mathrm{u} / \mathrm{A}=2\left(\mathrm{~b}_{\mathrm{fi}}+\mathrm{t}_{\mathrm{fi}}\right) / \mathrm{b}_{\mathrm{fi}} \mathrm{t}_{\mathrm{fi}}$

- para a mesa superior sobreposta por laje maciça:

$\mathrm{u} / \mathrm{A}=\left(\mathrm{b}_{\mathrm{fs}}+2 \mathrm{t}_{\mathrm{fs}}\right) / \mathrm{b}_{\mathrm{fs}} \mathrm{t}_{\mathrm{fs}}$

Com relação às equações (1) e (2) e à figura 13, $\mathrm{b}_{\mathrm{fi}}$ é a largura da mesa inferior, $\mathrm{t}_{\mathrm{fi}}$ é a espessura da mesa inferior, $b_{\mathrm{fs}}$ é a largura da mesa superior e $\mathrm{t}_{\mathrm{fs}}$ é a espessura da mesa superior.

Para a laje de concreto, a NBR 13423 (ABNT, 1999), prescreve que a variação de temperatura ao longo da altura da laje de concreto, apesar de decrescente da face inferior (exposta ao incêndio) para a face superior, seja tomada como constante e igual a um valor médio, $\theta_{c}$, determinado por meio de equação escrita na forma: 


$$
\theta_{\mathrm{c}}=\frac{1}{\mathrm{~h}_{\mathrm{ef}}} \sum_{\mathrm{j}=1}^{\mathrm{n}} \theta_{\mathrm{c}, \mathrm{j}} \mathrm{e}_{\mathrm{j}}
$$

Na última equação, $h_{\text {ef }}$ é definido conforme item A.2.2 da NBR 14323 (ABNT, 1999), n é o número de fatias da laje e $\theta_{c, j}$ e e são, respectivamente, a temperatura e a espessura das " $n$ " fatias em que a laje é dividida. Considerou-se a não ocorrência de transferência de calor entre as partes da viga de aço, bem como a não ocorrência de transferência de calor entre a mesa superior e a laje de concreto. A figura 14 ilustra a distribuição de temperatura na seção transversal da viga mista ao longo do tempo.

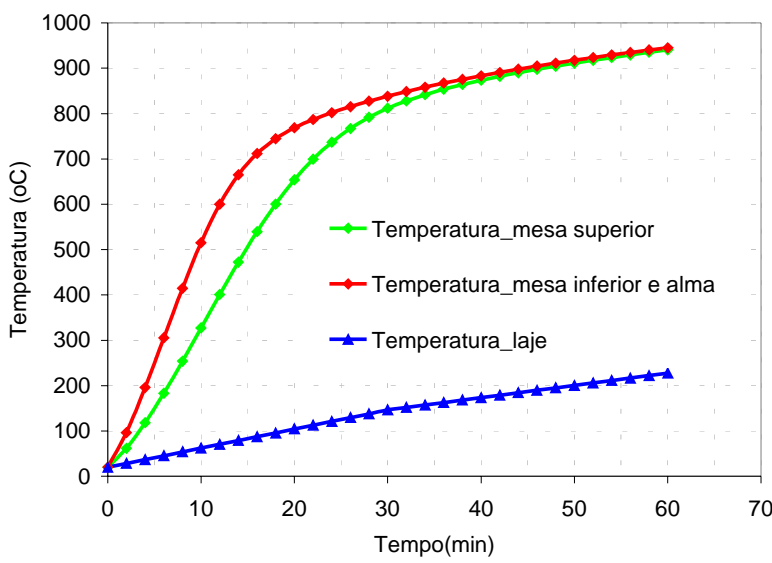

Figura 14. Distribuição da temperatura na seção transversal do modelo em situação de incêndio.

\section{Comparação entre resultados numéricos e experimental}

Análise em temperatura ambiente

São apresentados, neste item, os resultados obtidos para o modelo numérico de viga mista simplesmente apoiada em temperatura ambiente, cujas dimensões da seção transversal, tipo de carregamento aplicado e comprimento do vão, estão ilustrados na figura 15.

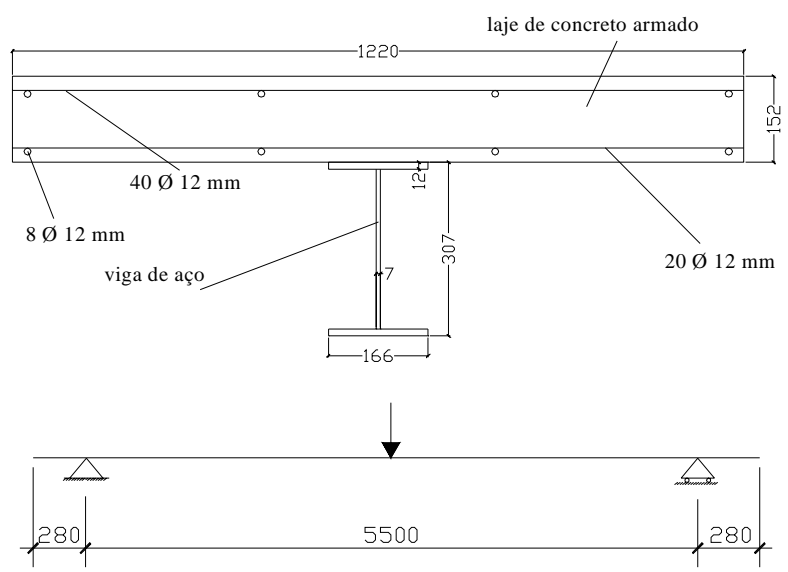

Figura 15. Dimensões utilizadas no modelo numérico em temperatura ambiente (unidade em $\mathrm{mm}$ ).

A tabela 1 apresenta as propriedades consideradas para as armaduras e viga de aço, bem como para o concreto, em que são especificadas as correspondentes resistências à compressão $\left(f_{c k}\right)$ e a relação existente entre a resistência última à tração uniaxial $\left(f_{t}\right)$ e à compressão $\left(f_{c k}\right)$. Estes dados estão em concordância com as relações constitutivas apresentadas no item 4.2.2.

Tabela 1. Propriedades dos materiais referentes ao modelo em temperatura ambiente.

\begin{tabular}{c|c|c|c|c|c|c|c}
\hline MATERIAL & $\mathrm{E}\left(\mathrm{kN} / \mathrm{cm}^{2}\right)$ & $\mathrm{E}_{1}\left(\mathrm{kN} / \mathrm{cm}^{2}\right)$ & $\sigma_{\mathrm{p}}\left(\mathrm{kN} / \mathrm{cm}^{2}\right)$ & $\sigma_{\mathrm{y}}\left(\mathrm{kN} / \mathrm{cm}^{2}\right)$ & $\sigma_{\mathrm{u}}\left(\mathrm{kN} / \mathrm{cm}^{2}\right)$ & $\mathrm{f}_{\mathrm{ck}}\left(\mathrm{kN} / \mathrm{cm}^{2}\right)$ & $\mathrm{f}_{\mathrm{t}} / \mathrm{f}_{\mathrm{ck}}$ \\
\hline ARMADURA & 20500 & - & - & 60,0 & - & - & - \\
\hline $\begin{array}{c}\text { PERFIL } \\
\text { METÁLICO }\end{array}$ & 20500 & 205 & 21,14 & 30,2 & 45,0 & - & - \\
\hline $\begin{array}{c}\text { LAJE DE } \\
\text { CONCRETO }\end{array}$ & 3104 & - & - & - & - & 2,7 & 0,12 \\
\hline
\end{tabular}

Nota: $\mathrm{E}_{\mathrm{c}}=9,5\left(f_{c k}+8\right)^{1 / 3}$, sendo que $\mathrm{E}_{\mathrm{c}} \mathrm{em} \mathrm{kN} / \mathrm{mm}^{2}$ e $\mathrm{f}_{\mathrm{ck}} \mathrm{em} \mathrm{N} / \mathrm{mm}^{2}$ (EUROCODE 2). 
A figura 16 ilustra a comparação entre valores numéricos e experimental, obtidos da relação entre o carregamento aplicado e os deslocamentos verticais que ocorrem no meio do vão da viga mista, para análise em temperatura ambiente e laje de concreto discretizada com os elementos C3D8R e S4R. O procedimento adotado foi do tipo "incrementaliterativo", utilizando-se como parâmetro de convergência numérica o resíduo de força com tolerância igual a 0,01 .

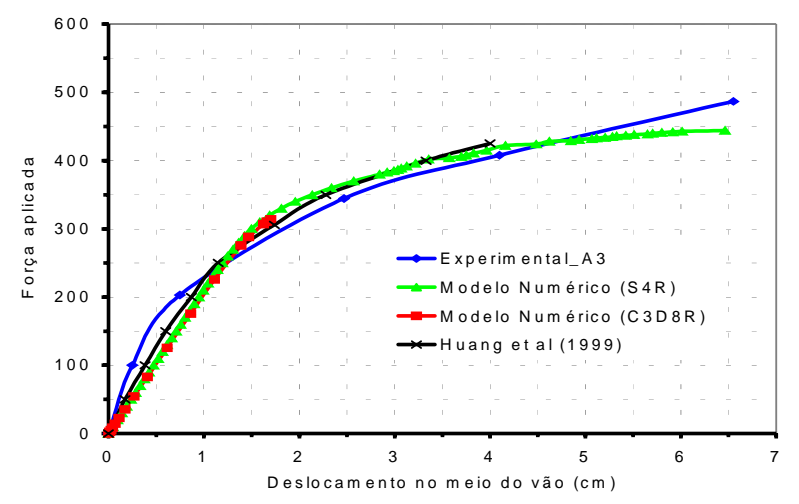

Figura 16. Comparação entre os resultados numéricos e experimentais.

O modelo numérico com a laje discretizada com o elemento $C 3 D 8 R$ apresentou convergência satisfatória dos resultados numéricos, quando comparado com os resultados experimentais, até um nível de carregamento correspondente a aproximadamente $314 \mathrm{kN}$, quando, então, a execução do programa foi interrompida em resposta a instabilidades verificadas no processo de convergência.

Foi observado que os problemas de instabilidade numérica ocorreram quando da consideração da nãolinearidade do material concreto, com forte influência em regiões com elevadas tensões de tração.
Aparentemente, os aspectos de instabilidade estão associados, provavelmente, a possíveis limitações do modelo "CONCRETE" quando associado ao elemento sólido C3D8R, disponibilizado pelo ABAQUS.

O modelo numérico com a laje de concreto discretizada com o elemento Shell S4R apresentou uma convergência satisfatória dos resultados numéricos quando comparado com os experimentais até um nível de carregamento correspondente a aproximadamente $450 \mathrm{kN}$, com boa aproximação entre os resultados numéricos e experimentais, inclusive no referente ao valor do carregamento último atingido.

Um aspecto importante com relação à figura 16 refere-se ao abatimento das curvas de ambos os modelos numéricos no trecho linear, quando comparadas à curva experimental. Tal fato pode, provavelmente, estar associado a algumas das propriedades estabelecidas para os materiais na modelagem numérica, as quais não foram disponibilizadas nos trabalhos de origem. Podem também ser considerados eventuais problemas de vinculação e acomodações, entre outros.

\section{Análise em situação de incêndio sem revestimento térmico}

São apresentados neste item os resultados obtidos por meio de análise numérica para o modelo de viga mista simplesmente apoiada em situação de incêndio, cujas dimensões da seção transversal, o tipo de carregamento estático aplicado (F) na laje de concreto e a ação térmica aplicada na mesa inferior da viga de aço, estabelecida pela curva ISO 834, estão ilustrados na figura 17. 


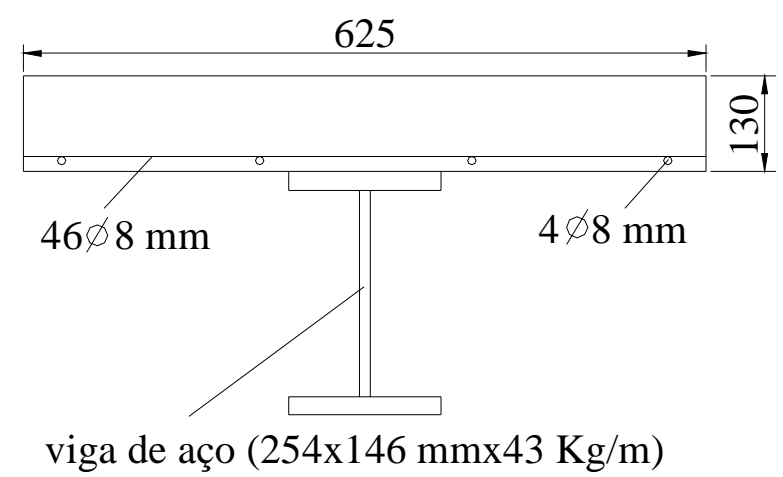

TESTE 15: $(\mathrm{F}=32,47 \mathrm{kN})$

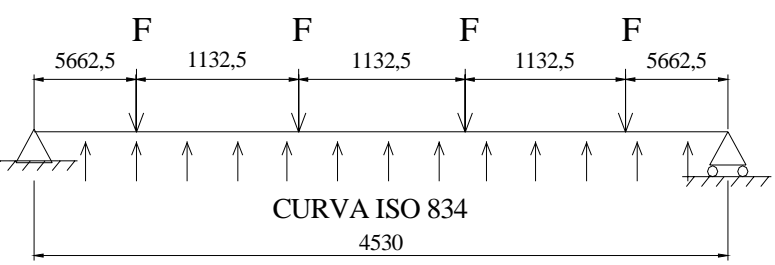

A tabela 2 apresenta os valores nominais das propriedades adotadas para o aço e para o concreto em temperatura ambiente, descritos por Wainman e Kirby (1988 apud HUANG; BURGESS; PLANK, 1999)nos testes de resistência ao fogo, bem como apresenta os coeficientes de dilatação térmica utilizados para o aço e para o concreto, de acordo com os valores recomendados no projeto de revisão da norma brasileira NBR 14323 (ABNT, 1999). Por simplificação, estes valores não estão em função da temperatura, ou seja, foram adotados constantes.

Figura 17. Dimensões utilizadas no modelo numérico em situação de incêndio (unidade em mm).

Tabela 2. Propriedades dos materiais referentes ao modelo em situação de incêndio.

\begin{tabular}{c|c|c|c|c|c|c|c}
\hline MATERIAL & $\mathrm{E}\left(\mathrm{kN} / \mathrm{cm}^{2}\right)$ & $\sigma_{\mathrm{p}}\left(\mathrm{kN} / \mathrm{cm}^{2}\right)$ & $\sigma_{\mathrm{y}}\left(\mathrm{kN} / \mathrm{cm}^{2}\right)$ & $\sigma_{\mathrm{u}}\left(\mathrm{kN} / \mathrm{cm}^{2}\right)$ & $\begin{array}{c}\mathrm{f}_{\mathrm{ck}} \\
\left(\mathrm{kN} / \mathrm{cm}^{2}\right)\end{array}$ & $\mathrm{f}_{\mathrm{t}} / \mathrm{f}_{\mathrm{ck}}$ & $\begin{array}{c}\alpha \\
\left(10^{-60} \mathrm{C}^{-1}\right)\end{array}$ \\
\hline ARMADURA & 20500 & - & 60,0 & - & - & - & 14 \\
\hline PERFIL METÁLICO & 20500 & 17,85 & 25,5 & 40,0 & - & - & 14 \\
\hline LAJE DE CONCRETO & 3180 & - & - & - & 3,0 & 0,12 & 18 \\
\hline
\end{tabular}

Nota: $E_{c}=9,5\left(f_{c k}+8\right)^{1 / 3}$, sendo que $E_{c}$ em kN/mm e $f_{c k}$ em N/mm² (EUROCODE 2).

Realizadas as primeiras simulações com a malha discretizada com elemento C3D8R, observou-se que o processo de convergência, após o final da aplicação do carregamento estático e início do carregamento térmico, foi interrompido para uma temperatura de aproximadamente $60{ }^{\circ} \mathrm{C}$ (medida na mesa inferior da viga) devido ao aparecimento de fissuras na parte inferior da laje. Essa interrupção ocorreu devido ao fato de os materiais aço e concreto apresentarem diferentes coeficientes de dilatação térmica e, conseqüentemente, diferentes deformações térmicas quando da aplicação dos incrementos de temperatura, principalmente na interface entre viga e laje.

A figura 18 ilustra a comparação entre valores numéricos e experimental, obtidos da relação entre a temperatura aplicada na mesa inferior da viga de aço e os respectivos deslocamentos verticais que ocorrem no meio do vão da viga mista em situação de incêndio, para laje discretizada com os elementos C3D8R e S4R. 


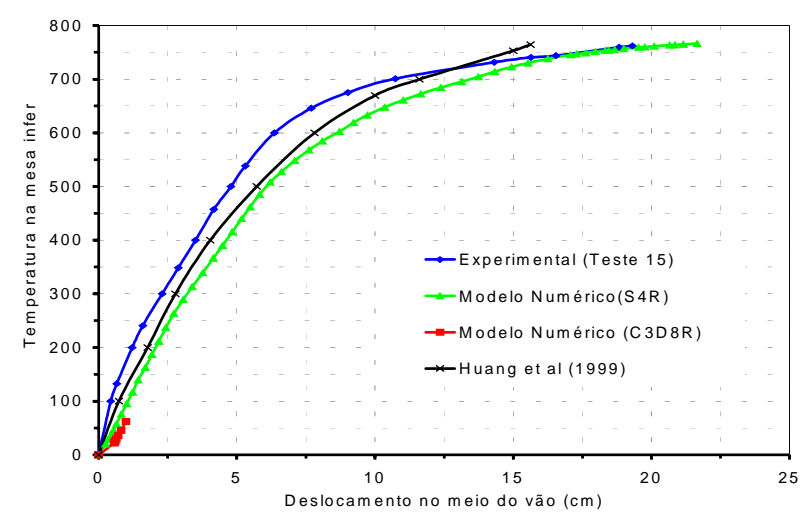

Figura 18. Comparação entre os resultados numéricos e experimentais.

Com relação ao modelo numérico em que a laje foi discretizada com o elemento S4R, é possível perceber novamente um melhor comportamento quando comparado àquele discretizado com elementos C3D8R, conforme já verificado nos resultados obtidos com o modelo numérico em temperatura ambiente.

É importante salientar que os procedimentos adotados para determinação da temperatura no elemento estrutural e, conseqüentemente, a determinação dos coeficientes de redução para os materiais foram estabelecidos com base nos valores prescritos no texto base do Projeto de Revisão da NBR 14323:1999. Por causa disso, podem, eventualmente, ocorrer diferenças entre valores numéricos e experimentais, já que se trata de um método simplificado de dimensionamento em que não se considera transferência de calor entre as partes que constituem o perfil metálico, ou entre a mesa superior da viga e a laje de concreto.

Ainda, por simplificação, permite admitir que a distribuição de temperatura na laje, apesar de decrescente da face inferior para a face superior, seja tomada como constante e igual ao seu valor médio.

\section{Conclusões}

A proposta do presente trabalho objetivou avaliar o comportamento global de vigas mistas aço-concreto simplesmente apoiadas, em temperatura ambiente e em situação de incêndio, por meio de modelos numéricos tridimensionais, utilizando o programa computacional ABAQUS versão 6.3-1.

Verificou-se que os modelos numéricos cuja laje foi discretizada com o elemento C3D8R não conduziram a resultados satisfatórios para as análises em temperatura ambiente e em situação de incêndio, em conseqüência de problemas de instabilidade numérica verificados no processo de convergência dos resultados, quando da consideração do modelo CONCRETE para modelos construídos com o elemento finito $\mathrm{C} 3 \mathrm{D} 8 \mathrm{R}$, principalmente para regiões predominantemente tracionadas.

Os modelos numéricos para análises em temperatura ambiente e em situação de incêndio, cuja laje foi discretizada com elemento S4R, conduziram a resultados satisfatórios quando comparados com os resultados experimentais. De fato, por apresentar formulação cujas funções aproximadoras são polinômios de graus maiores quando comparada àquela do elemento $\mathrm{C} 3 \mathrm{D} 8 \mathrm{R}$, o elemento $\mathrm{S} 4 \mathrm{R}$ possui melhor desempenho e maior eficiência para situações em que predomina a ocorrência de esforços de flexão.

Para que o modelo numérico discretizado com elementos C3D8R atinja nível de carregamento (desempenho) próximo àquele obtido com elementos S4R, faz-se necessária uma malha de elementos C3D8R com grau de refinamento considerável, resultando em um esforço computacional significativo. Para a análise proposta neste trabalho, a utilização do elemento S4R resulta ser mais adequada.

Com referência às ferramentas utilizadas na modelagem numérica, cabe levar em consideração alguns fatores, tais como a utilização de outros critérios de ruptura para o concreto, a utilização de outros elementos disponíveis na biblioteca do ABAQUS, bem como a elaboração de rotinas que 
desconsiderem a parcela tracionada do concreto. Esses fatores podem possibilitar tanto em temperatura ambiente como em situação de incêndio, a melhores resultados dos modelos numéricos aqui propostos.

\section{Agradecimentos}

Os autores do presente trabalho agradecem à FAPESP - Fundação de Amparo à Pesquisa do Estado de São Paulo o apoio concedido no desenvolvimento do trabalho em questão.

\section{Referências}

ABNT. NBR 8800:1986 - Projeto e execução de estruturas de aço de edifícios. Rio de Janeiro, 1986.

ABNT. NBR 14323:1999-Dimensionamento de estruturas de aço de edifícios em situação de incêndio Procedimento. Rio de Janeiro, 1999.

ABNT. NBR 14432:2000 - Exigências de resistência ao fogo de elementos construtivos de edificações Procedimento. Rio de Janeiro, 2000.

CHAPMAN, J. C., BALAKRISHNAN, S. Experiments on composite beams. The Structural Engineer, v. 42, n. 11, p. 369-383, 1964.

CLARET, A. M.. Resistência ao fogo de vigas mistas açoconcreto modeladas pelo método dos elementos finitos. In: JORNADAS SUDAMERICANAS DE INGENIERIA ESTRUCTURAl, 2000, Punta Del Este. Anais...Punta Del Este, 2000.

EUGHAZOULI, A. Y., IZZUDDIN, B. A. Response of idealized composite beam-slab systems under fire conditions. Journal of Constructional Steel Research, UK, v. 56, p. 199-224, 2000.

EUROPEAN COMMITTEE FOR STANDARDIZATION. ENV 1992-1-2: Eurocode 2 - Design of concrete structures. Part 1-2: General rules - Structural fire design. Brussels, 1995.
EUROPEAN COMMITTEE FOR STANDARDIZATION ENV 1994-1-2: Eurocode 4 - Design of composite steel and concrete structures. Part 1-2: General rules and rules - Structural fire design. Brussels, 1994.

GATTESCO, N. Analytical modeling of nonlinear behavior of composite beams with deformable connection. Journal of Constructional Steel Research, Italy, v.52, p.195-218, 1999.

HIBBITT; KARLSSON ; SORENSEN, Inc. Abaqus Theory Manual \& Users Manuals, Version 6.3 Pawtucket, RI, USA, 2002.

HUANG, Z.; BURGESS, I.W.; PLANK, R. J. The influence of shear connectors on the behavior of composite steelframed building in fire. Journal of Constructional Steel Research, London, v.51, p.219-237, 1990

MALITE, M. Sobre o cálculo de vigas mistas açoconcreto: ênfase em edifícios. 1990. Dissertação (Mestrado ) -Escola de Engenharia de São Carlos, Universidade de São Paulo, São Carlos.

MALITE, M. Análise do comportamento estrutural de vigas mistas aço-concreto constituídas por perfis de chapa dobrada. 1993. Tese (Doutorado) - Escola de Engenharia de São Carlos, Universidade de São Paulo, São Carlos.

OVEN, V. A.; BURGESS, I. W.; PLANK, R. J.; ABUD WALI, A. A. An analytical model for the analysis of composite beams with partial interaction. Computers and Structures, Elmsford, v.62, n.3. p.493-504, 1990.

RODRIGUES, F. C. Comportamento de Estruturas Constituídas por Perfis Formados a Frio em Temperatura Ambiente e em Temperatura Elevada. In: SEMINÁRIO INTERNACIONAL "O USO DE ESTRUTURAS METÁLICAS NA CONSTRUÇÃO CIVIL, 2., 1999, Belo Horizonte. Anais... Belo Horizonte, 1999.

SILVA, V.P., FAKURY, R.H. Normas Brasileiras de Estruturas de Aço em Situação de Incêndio. In: JORNADAS SUDAMERICANAS DE INGENIERIA ESTRUCTURAL, 29., 2000, Punta Del Este. Anais... Del Este,2000.

TRISTÃO, G. A. .Comportamento de conectores de cisalhamento em vigas mistas aço-concreto com análise da resposta numérica.2002. Dissertação (Mestrado) Escola de Engenharia de São Carlos, Universidade de São Paulo, São Carlos.

VIEST, I. Review of research on composite steel - concrete beams. Proceeding ASCE, v. 86, ST6, p.1-21, 1960. 